\title{
The Self-Inflicted Dermatoses: A Critical Review
}

\author{
Madhulika A. Gupta, M. D., F.R.C.P.(C)* \\ Psychodermatology Clinic, Department of Psychiatry, Toronto Western Hospital, University of Toronto, \\ Toronto, Ontario, Canada
}

\author{
Aditya K. Gupta, M.A., M.D. \\ Department of Dermatology, University of Michigan, Ann Arbor, Michigan
}

\author{
Herbert F. Haberman, M.D., F.R.C.P.(C) \\ Division of Dermatology, Department of Medicine, Toronto Western Hospital, University of Toronto, Toronto, \\ Ontario, Canada
}

\begin{abstract}
The self-inflicted dermatoses, namely dermatitis artefacta, neurotic excoriations, and trichotillomania, have been reported to be associated with various degrees of psychopathology in the dermatologic literature, but have received surprisingly little emphasis in the psychiatric literature. This probably reflects, firstly the fact that most of these patients initially deny any psychologic problems and hence may not receive psychiatric interventions, and secondly a lack of adequate collaboration between the psychiatrist and dermatologist. These disorders may be associated with serious sequelae, such as suicide and repeated major surgical procedures. Their treatment is also primarily psychiatric. This article critically reviews the literature and comments upon the salient clinical features and treatments for these disorders, which are relevant for the psychiatrist doing consultation-liaison work. Knowledge of these disorders is important in the evaluation of any psychiatric patient, as these disorders are essentially a cutaneous sign of psychopathology.
\end{abstract}

The self-inflicted dermatoses have received little attention in the psychiatric literature, and surprisingly few studies have evaluated the psychopathology of these patients [1], even though in the dermatologic literature these disorders have been classified as being "exclusively emotional in origin" [2], and on occasion have been reported to be associated with suicide [3]. As most of these patients

\footnotetext{
${ }^{*}$ Currently also with the Department of Psychiatry, University of Michigan, Ann Arbor, Michigan.

usually deny any psychiatric problems initially, which frequently leads to a delay in psychiatric intervention, they are typically first seen by the dermatologist. Knowledge of these disorders is therefore especially important for the psychiatrist doing consultation-liaison work with dermatology. Furthermore, in most instances these dermatoses are readily visible and are a "cutaneous sign" of psychopathology, and therefore knowledge of these disorders is useful in the psychiatric assessment of any patient.

In the narrow sense, the skin is the interface between the individual and the physical and social environment, and an important medium for communication. This fact, along with its easy accessibility, probably makes the skin more vulnerable to self-inflicted lesions. This article critically reviews the literature on the three major self-inflicted dermatoses, namely, dermatitis artefacta, neurotic excoriations, and trichotillomania or traumatic alopecia. In our experience at the Psychodermatology Clinic, psychiatric intervention is often the most crucial element in the treatment of these patients. The purpose of this paper is to a) alert the clinician that a potentially life-threatening and treatable psychiatric disorder may underlie some of these dermatologic disorders, and b) review the salient clinical features and psychiatric treatments that have been reported to be effective in these frequently chronic cutaneous conditions. 


\section{Review of the Literature}

The majority of the studies [4-19] have not used controls when evaluating the psychiatric features or treatments for the various self-inflicted dermatoses, nor have they stated the operational definitions of the various psychiatric disorders diagnosed. In spite of these methodologic problems, the current literature delineates some distinctive features of these disorders that are of significant clinical relevance.

\section{Dermatitis Artefacta}

\section{Definition}

Dermatitis artefacta is a term that describes cutaneous lesions that are wholly self-inflicted $[2,20]$. The patients typically deny the self-inflicted nature of these lesions $[2,20]$.

\section{Demographic Features}

The incidence of dermatitis artefacta among der matologic patients has been reported to $0.3 \%$ [20]. There is a predominance of this disorder among females, with a male-to-female ratio of at least 1 to 4 $[4-6,15,21]$ in the various studies. The age at onset of symptoms spans a broad range from 9-73 years $[4-6,15]$.

\section{Dermatologic Features}

The lesions have wide-ranging morphologic features and are often bizarre looking (Fig. 1), with sharp geometric borders (Fig. 2) surrounded by normal looking skin (Figs. 1 and 2) $[2,20,22,23]$ They may present as blisters, purpura, ulcers, erythema, edema, sinuses, or nodules, depending upon the means employed by the patient to create the lesions [24], such as deep excoriation by fingernails or other sharp object, chemical and thermal burns [2], occlusion of circulation around the limbs or digits $[2,5,23]$, and so on. Cutaneous factitial disease has been reported to mimic Weber-Christian syndrome [25], subcutaneous emphysema [26], bullous pemphigoid [27], and cellulitis [23]. Full-thickness skin loss or severe scarring resulting from the self-inflicted lesions may necessitate extensive plastic surgery $[28,29]$. In a review of 130 cases of dermatitis artefacta, 22 women required surgery, with 12 needing amputations [21].

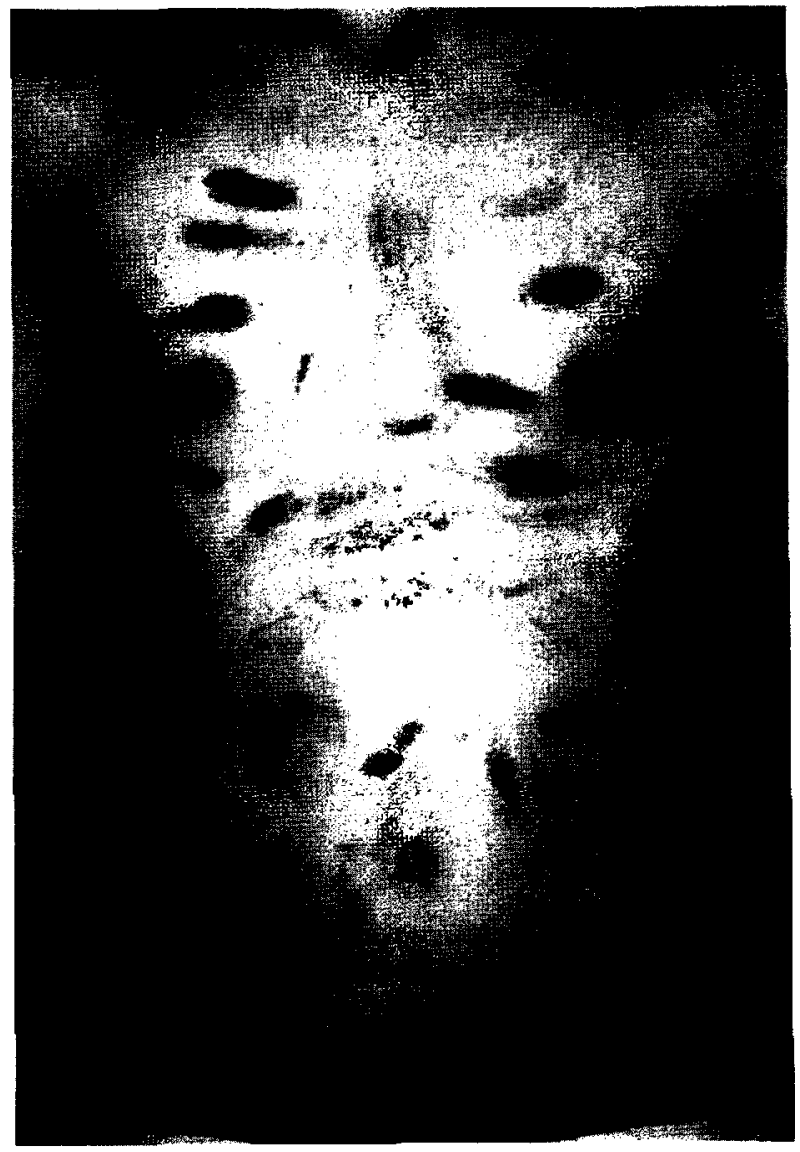

Figure 1. Bizarre looking self-inflicted lesions in dermatitis artefacta. The skin surrounding the lesions is normal looking.

\section{Psychiatric Features}

Self-inflicted dermatologic lesions have been associated with mental retardation, psychosis, Munchausen's syndrome, and malingering [6]. These disorders are present in only a small minority of these patients, however, and in most instances obvious evidence of secondary gain is not present [21]. The most consistent observation appears to be an underiying immature personality, with the dermatitis artefacta being "an appeal for help" $[4,23]$. After following up these patients for up to 22 years, Sneddon and Sneddon [5] observed that dermatitis artefacta was only one incident in a long history of "psychogenic illness," and report that $5 \%$ of their patients also developed anorexia nervosa. Interestingly, these patients were young women with immature personality configurations, who developed both disorders in the context of a difficult life situation. In a survey of patients with 


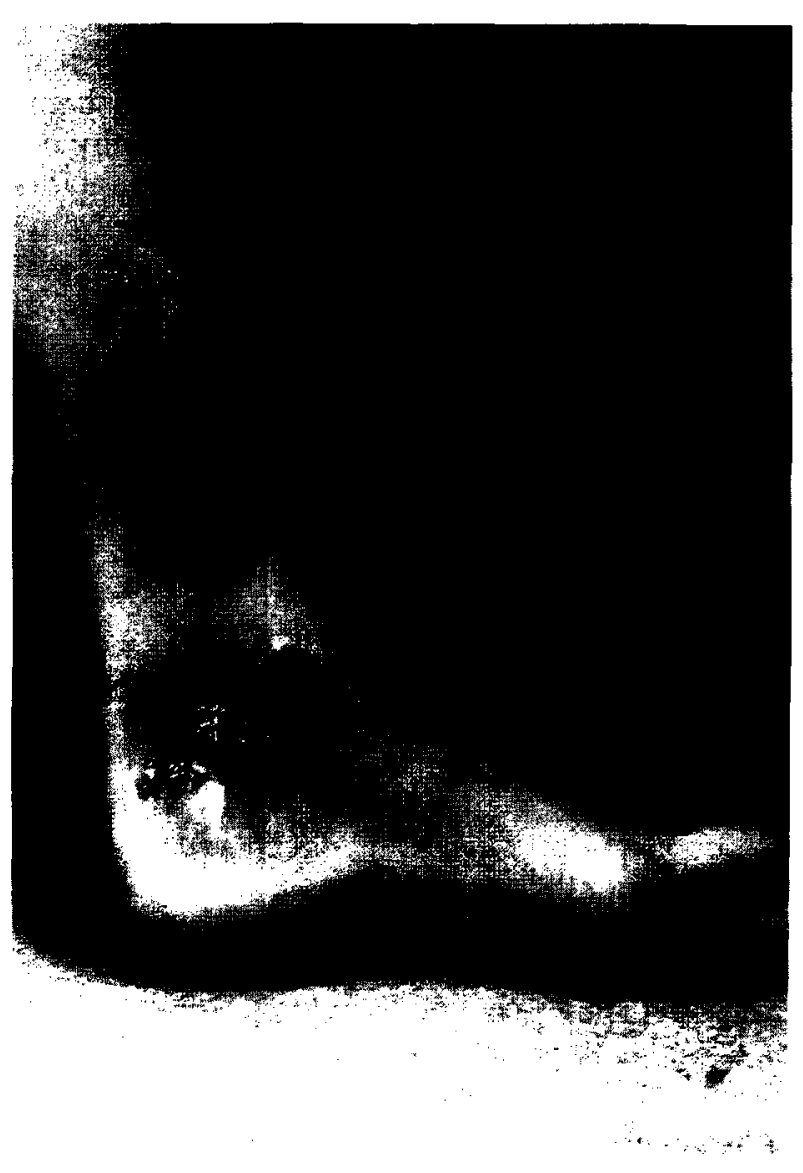

Figure 2. $A$ chronic, self-induced cutaneous ulcer over the medial malleolus. The prominent hyperpigmentation is partly post-inflammatory in reaction to self-inflicted trauma, and also due to topical Minocycline which was used to treat the ulcer.

different forms of self-inflicted dermatoses, Krupp [15] reports a $46 \%$ prevalence of depressive illness; however, studies that have looked at patients with dermatitis artefacta alone report only a $9 \%$ prevalence of depressive illness among these patients [5]. There is a very low incidence of suicide among these patients $[23,30]$. Other disorders reported include multiple personality disorder [31]. In the pediatric age group, the possibility of child abuse must always be ruled out $[32,33]$.

Loss or threatened loss, marital difficulties $[4,5,15]$, and increased social isolation, especially among the elderly [30], may precede dermatitis artefacta.

\section{Diagnosis}

Early diagnosis is important as this may prevent unnecessary surgery and chronic morbidity [21]. Typically, bizarre looking necrotic lesions appear rather suddenly in areas that are easily accessible to the patient [34]. In the right-handed person, the left side is usually involved $[5,21]$. The lesions are usually asymmetric, may appear singly or in crops, with no history of a primary papule or vescicle [34]. The patients are typically not able to describe how the lesions evolved, and their histories have been described as "hollow" [24], when the dermatologic symptoms are evaluated. Diagnosis is usually confirmed by biopsy which indicates lack of a primary disease process [34]. The lesions heal if occlusive dressing or a plaster cast $[24,34,35]$ is used. Lesions are frequently produced at sites that may have been suggested to the patient by the physician, as being a likely site for the next lesion [21,34].

\section{Treatments}

Most authors recommend a supportive and empathic approach $[2,4,5,22,23]$, avoiding direct discussion regarding the self-inflicted nature of the lesions. Few have suggested that direct confrontation is helpful [21]. Once a satisfactory therapeutic relationship is established, a more insight-oriented psychotherapeutic approach may be helpful $[4,30]$. The self-mutilative behavior has been interpreted as "a desire for self-punishment to achieve relief from tensions caused by fear and guilt," an attempt to "test the tolerance" of others, and as "exhibitionistic" $[4,30]$. Twenty percent of these patients have been reported to have experienced the loss of a parent or sibling by separation or death in the first decade of life [15], and it is likely that developmental problems resulting from this would be the focus of treatment in some patients. In many cases, the disorder develops in the context of a difficult life situation $[4,5,15]$, and often recovery occurs only after improvement in the life situation [5]. Schoolrelated problems were present in $60 \%$ of children with dermatitis artefacta [4]. Among adolescents and adults, problems in all major areas-sexual, marital, family and work-related-were common $[4,15]$. Illness, accident, or bereavement have been observed to precede 19\% [4] to 33\% [15] of cases. Environmental manipulation may be facilitated, for example in the case of a child through family therapy or change of schools, and among the socially isolated elderly by mobilizing social support. Other helpful adjuncts include relaxation exercises [5], and a short course of antianxiety or antidepressant medications [4] where indicated. 


\section{Course and Prognosis}

The course and prognosis of dermatitis artefacta vary considerably. This is most likely related to the nature of the underlying psychiatric disorder. In some instances, recovery occurs after the initial psychiatric contact, whereas in other cases, the disorder may persist for decades [4]. Sneddon and Sneddon [5] followed up 33 patients for 22 years and observed that $30 \%$ of these patients continued to produce lesions 12.4 years after onset of symptoms. A large number of these patients were diagnosed as having "immature" personalities and treatments employed were not clearly stated. Contrary to other reports, Hawkings et al. [6] have described this disorder as "self-righting" with no cases persisting beyond the fourth decade, and have compared its course with anorexia nervosa. The prognosis is reported to be better in the younger age group where symptoms arise primarily in the context of a disturbed home situation $[4,30]$.

\section{Neurotic Excoriations}

\section{Definition}

Neurotic excoriations are lesions produced by the patient as a result of repetitive self-excoriation which may be initiated by an itch, "a disturbing sensation" in the skin distinct from pruritus, or because of an urge to excoriate a benign irregularity on the skin $[2,3,20,36,37]$. This initiates and perpetuates the "itch-scratch" cycle [38], which in some patients becomes a true compulsive ritual [3]. Unlike dermatitis artefacta, the patients typically acknowledge the self-inflictive nature of their lesions [36].

\section{Demographic Features}

There is a $2 \%$ incidence of neurotic excoriations among dermatology clinic patients [20] and a 9\% prevalence among inpatients with pruritus [39], with a predominance among females, ranging from $52 \%$ to $92 \%[3,7,11,12]$ in the various studies. Most studies report a mean age of onset between 30 and 45 years $[3,7,14]$; some authors, however, have reported a peak incidence in the 20s [36].

\section{Dermatologic Features}

Unlike the frequently bizarre looking lesions of dermatitis artefacta, the lesions in neurotic excoriations do not stand out as being unusual, and do not have the potential to mimic other dermatologic disorders. They are typically a few millimeters in diameter, weeping, crusted, or scarred, with postinflammatory hypopigmentation or hyperpigmentation $[20,36]$. The lesions may range in number from a few to several hundred and in chronic cases, scarring may be the only sign [20] (Fig. 3). The lesions are distributed in areas that the patient can reach, typically affected regions being the upper and lower extremities, face and upper back $[20,36]$. The repetitive self-excoriation can also exacerbate a preexisting dermatosis [3].

\section{Psychiatric Features}

The most consistent psychiatric disorders reported in association with neurotic excoriations are a personality with perfectionistic and compulsive traits $[3,7-9,15]$ and depression $[3,7,15]$. Unlike dermatitis artefacta, suicide has been reported to be more frequent in neurotic excoriations [3]. Other psychopathologies include psychosis [9], "conversion reactions" [7,9], "hysteria" [11], hypochondriasis [3], and anxiety states [3,9]. Up to one third of these patients also have tension or migraine headaches and gynecologic symptoms related to menstruation [3]. It is possible that in some instances, these symptoms may indicate an underlying somatization disorder.

Many have observed that these patients have difficulty expressing anger $[3,36,37,40]$ and situations that provoke aggressive impulses may precipitate the scratching and pruritus. Electroencephalographic (EEG) abnormalities, consisting of nonfocal theta activity in the temporal regions in $52 \%$ with neurotic excoriations versus $25 \%$ of psychiatric outpatient controls [41] have been proposed to be related to abnormalities in the modulation of aggression, since they are similar to EEG abnormalities in psychopaths.

Psychosocial stressors typically involving marriage, family, or work [3,9] have been reported to precede neurotic excoriations in $33 \%-98 \%$ of patients $[3,20]$. We have observed onset of neurotic excoriations following physical debility due to illness or aging among individuals with strongly compulsive personality traits [42]. The development of repetitive self-excoriation following decreased physical mobility is similar to other repetitive motor phenomena like tics that have been observed in wild animals held in captivity [43]. This is consistent with the ethologic view that scratching 


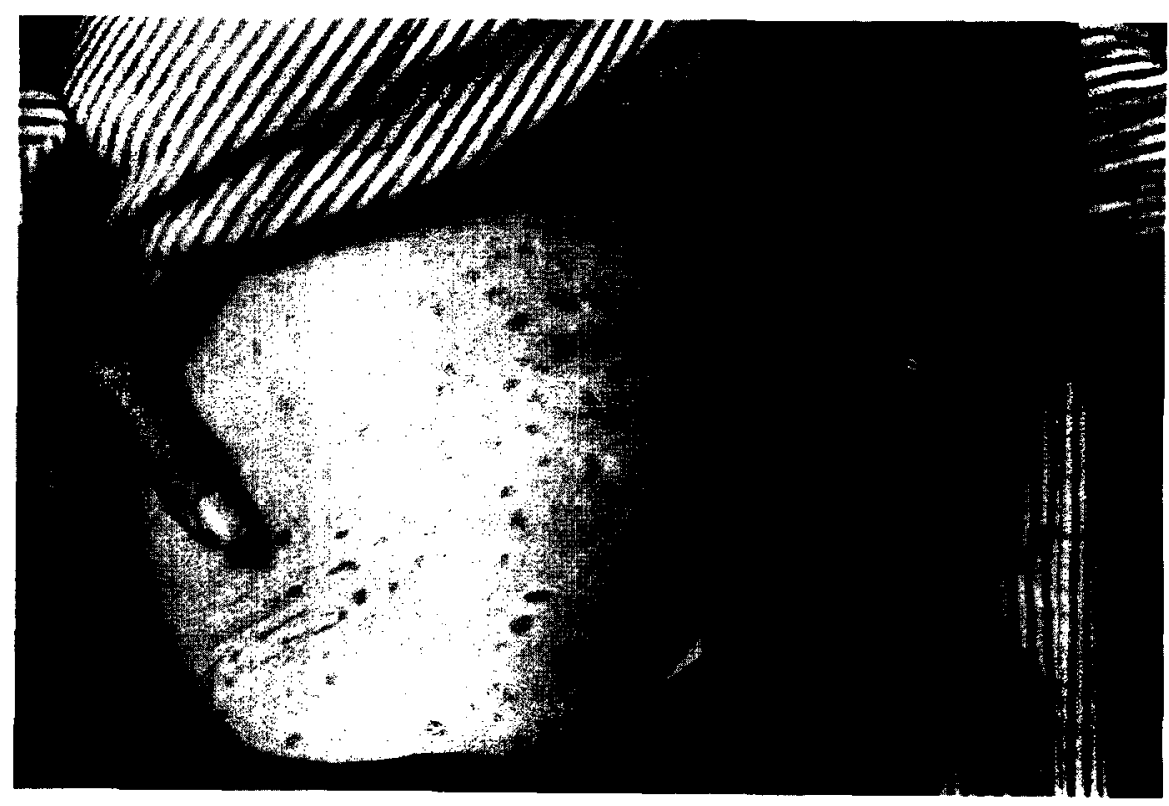

Figure 3. Numerous scarred cutaneous lesions with hyperpigmentation, as a result of repetitive self-excoriation, in a patient with neurotic excoriations.

is a "derived" activity arising in reaction to frustration [44].

\section{Diagnosis}

Diagnosis must include investigations for other systemic and local causes of pruritus. The patients acknowledge that their scratching perpetuates the disorder. The histopathology of these lesions is consistent with repetitive localized trauma to the skin [45].

\section{Treatment}

Improvement in the mental state has been associated with improvement in the cutaneous lesions [3]. Freunsgaard [3] observes that the psychiatric interview alone can initiate improvement in some patients. An empathic supportive approach $[7,46]$ has been reported to be significantly more effective than insight-oriented psychotherapy [14], which often exacerbates the symptoms. Benzodiazepines [47,48], Amitriptyline 50-75 mg/day [7], and Pimozide 4-6 mg/day [49] have been used to treat neurotic excoriations. It is not clear whether these patients had an underlying depressive illness or psychotic symptomatology. The efficacy of antipsychotics and antidepressants is most likely not relat- ed to their antihistaminic effects alone, as clinically antihistamines have primarily a sedating, rather than a specific antipruritic effect [38], except in histamine-mediated pruritic states.

\section{Course and Prognosis}

The mean duration of symptoms has been reported to be 5 years (range 6 months to 12 years) [14]. In Freunsgaard's study [3], 52\% had symptoms for over 1 year, with most having symptoms for 10-12 years. Prognosis is better when the lesions have been present for less than 1 year [3] and worse when other physical complaints such as muscle tension headaches are also present $[9,10]$.

\section{Trichotillomania (Traumatic Alopecia)}

\section{Definition}

Trichotillomania is defined as nonscarring alopecia as a result of a compulsion to pluck out one's own hair $[1,36]$. The extracted hair may be chewed or swallowed $[1,36]$. The patients typically deny that the alopecia is self-induced $[16,50]$. This disorder should be distinguished from hair-pulling, which may be associated with thumb-sucking and nailbiting in children. 


\section{Demographic Features}

Trichotillomania appears to be a relatively rare disorder, with a prevalence of 5-60 per 10,000 in a child psychiatric setting [51]. Interestingly, among the self-inflicted dermatoses, this disorder is most well known in the psychiatric literature. In the various studies [16-19] 38\%-100\% of patients were reported to be female. The mean age at onset is typically 5-12 years [17-19].

\section{Dermatologic Features}

The hair of the scalp, eyebrows, eyelashes, beard, or pubic area are usually affected. The hair-plucking is often accomplished by twisting the strands around the fingers, followed by pulling of the hair [52]. This results in hairs of various lengths partially distributed over the area of alopecia [52]. An affected region is rarely completely devoid of hair [52] (Fig. 4). The areas of alopecia appear at regular intervals and tend to be in the same region of the scalp. Patients often complain of itching of the scalp. The term trychokyptomania has been used to describe a disorder similar to trichotillomania, where hairs are broken off instead of being completely pulled out [53].

\section{Psychiatric Features}

Most children with trichotillomania have been diagnosed as "neurotic" $[1,18,36]$, and some have observed an absence of serious psychopathology in the child [19], the disorder occurring primarily in the context of a disturbed parent-child relationship [19]. Greenberg et al. [17] observed that $84 \%$ of the mothers of these children were "highly pathologic" and $87 \%$ of the fathers "helpless and ineffectual." Depressive symptomatology has been reported in a significant number of adolescents with this symptom [17]. An overconcern about body weight has also been observed among these patients [17]. In this study [17], where patients had been referred from both dermatologic and psychiatric facilities, $10 \%$ were diagnosed as schizophrenic and $37 \%$ had borderline personality disorders. Stressful life situations have been known to precede the onset of symptoms [16-18]. Among children, precipitating factors include the birth of a sibling, poor peer relationships and academic difficulties in school $[17,51,54]$. The severity of the underlying psychiatric disturbance has not been related to the severity of the hair loss or involvement of multiple sites [18].

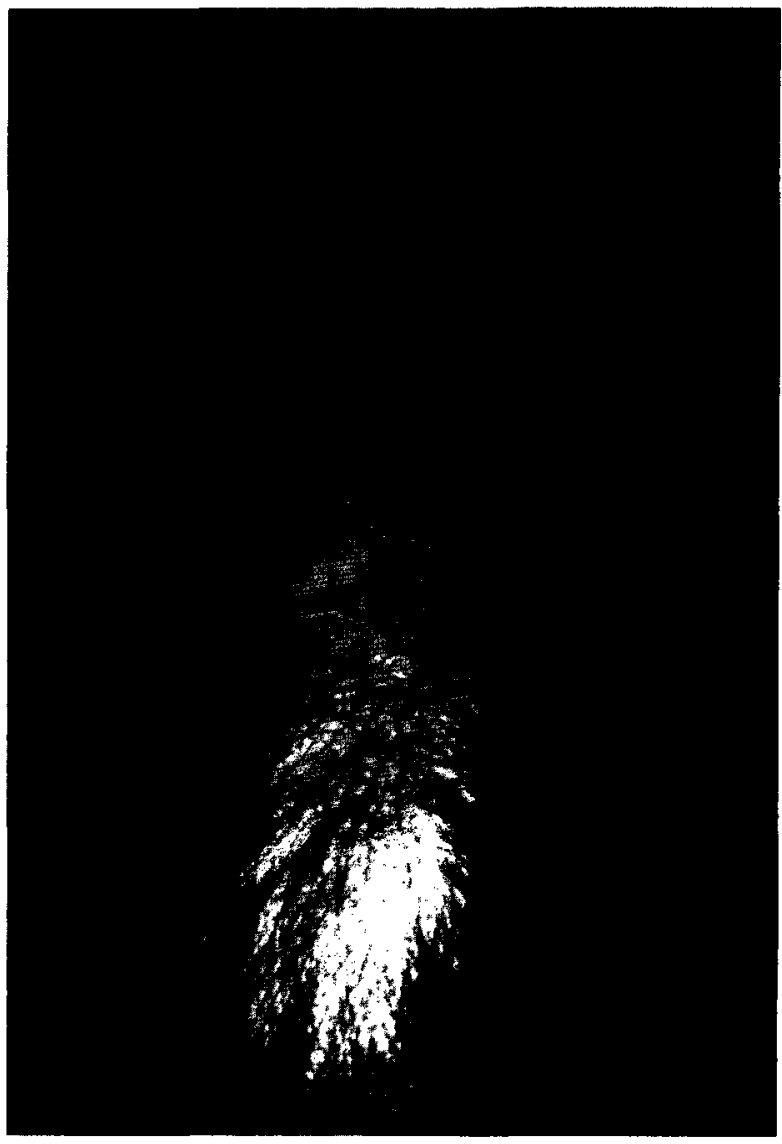

Figure 4. Alopecia secondary to trichotillomania. Note that the affected area is not completely devoid of hair.

\section{Diagnosis}

The patients often deny or rationalize the hairplucking behavior, and the parents also frequently demonstrate denial or rationalization [54]. Mueller et al. [18] have described characteristic changes in the skin biopsy, secondary to traumatic avulsion of the hair shafts, and suggest that a biopsy should be done to confirm the diagnosis. Affected areas of the scalp have been protected by bandage and reexamined after several days for evidence of hair regrowth. Differential diagnosis includes alopecia areata where circular areas of total alopecia appear suddenly and enlarge steadily.

\section{Treatment}

A wide range of treatment modalities have been used in an uncontrolled fashion. Treatment of the underlying disorder utilizing psychotherapy and 
family therapy in children [50], behavior therapy including thought stopping [55], and aversive conditioning [56,57], simple self-monitoring [58,59], hypnosis [60], and relaxation training [61], have all been reported to be effective. Chlorpromazine [62], Amitriptyline [63], and monoamine oxidase inhibitors [64] have also been used.

\section{Course and Prognosis}

In most instances, this disorder is chronic $[36,50]$ and there have been reports of symptoms lasting for up to 17 years [16].

\section{Discussion}

The self-inflicted dermatoses are a chronic heterogeneous groups of disorders, reported to be more common among females and are generally associated with different classes of psychopathology. Neurotic excoriations, with peak age at onset of 30 45 years, and trichotillomania, with peak age of onset at 5-12 years, are both compulsive self-mutilative behaviors manifesting as repetitive self-excoriation and compulsive hair-plucking, respectively. In the adult or adolescent, they are both commonly associated with depressive illness. In the child with trichotillomania, various forms of disturbed parent-child relationship may be present. Neurotic excoriations is the most common self-inflicted dermatosis and has been associated with suicide. Dermatitis artefacta has a much more wide ranging age of onset and is associated with a more heterogeneous group of psychiatric disorders, but it is most frequently encountered among individuals with immature personalities in the face of a stressful life situation. Some authors have compared the psychodynamics and course of this disorder with anorexia nervosa. Each patient suspected of having a self-inflicted dermatosis requires a complete physical and psychosocial assessment. Although currently there are no controlled studies evaluating the efficacy of psychiatric intervention in these patients, the literature suggests that management of the underlying psychiatric disorder is the most important feature in the treatment of the dermatologic lesions and in preventing possible serious sequelae such as suicide and repeated major surgical procedures in some of these patients.

We wish to thankJ. E. Rasmussen, M.D., Department of Dermatology, University of Michigan, for providing us with Figures 1, 2, and 4.

\section{References}

1. Whitlock FA: Psychophysiological aspects of skin disease. In Rook A (ed), Major Problems in Dermatology. London, Saunders, 1976, Vol 8, pp 90-109

2. Rook A, Wilkinson DS: Psychocutaneous disorders. In Rook A, Wilkinson DS, Ebling FJG (eds), Textbook of Dermatology, 3rd ed. Oxford, Blackwell, 1979, vol 2, pp 2023-2035

3. Freunsgaard K: Neurotic excoriations, a controlled psychiatric examination. Acta Psychiatr Scand (Suppl) 69:1-52, 1984

4. Fabisch W: Psychiatric aspects of dermatitis artefacta. Br J Dermatol 102:29-34, 1980

5. Sneddon I, Sneddon I: Self-inflicted injury: A follow-up study of 43 patients. Br Med J 1:527-530, 1975

6. Hawkings JR, Jones KS, Sim M, Tibbetts RW: Deliberate disability. Br Med J 1:361-367, 1956

7. Fisher BK, Pearce KI: Neurotic excoriations: A personality evaluation. Cutis 14:251-254, 1974

8. Beek CH: Self-inflicted lesions. Dermatologica 107:115- 123, 1953

9. Cormia FE: Basic concepts in the production and management of the psychosomatic dermatoses I. Br J Dermatol 63:83-92, 1951

10. Cormia FE: Basic concepts in the production and management of the psychosomatic dermatoses II. Br J Dermatol 63:129-151, 1951

11. Pusey WA, Senear FE: Neurotic excoriations with report of cases. Arch Dermatol Syphilol 1:270-278, 1920

12. Mackee GM: Neurotic excoriations. Arch Dermatol Syphilol 1:256-269, 1920

13. Calnan $C D, O^{\prime}$ Neill D: Itching in tension states. Br J Dermatol 64:274-280, 1952

14. Seitz PFD: Dynamically-oriented brief psychotherapy: Psychocutaneous excoriation syndromes. Psychosom Med 15:200-213, 1953

15. Krupp NE: Self-caused skin ulcers. Psychosomatics 18:15-19, 1977

16. Sanderson KV, Hall-Smith P: Tonsure trichotillomania. Br J Dermatol 82:343-350, 1970

17. Greenberg R, Sarner CA: Trichotillomania: Symptom and syndrome. Arch Gen Psychiatry 12:482-489, 1965

18. Muller SA, Winkelmann RK: Trichotillomania, a clinicopathologic study of 24 cases. Arch Dermatol 105:535-540, 1972

19. Oguchi T, Miura S: Trichotillomania: Its psychopathological aspect. Compr Psychiatry 18:177-182, 1977

20. Griesemer RD, Nadelson T: Emotional aspects of cutaneous disease. In Fitzpatrick TB, Eisen HZ, Wolff K, Freedberg IM, Austen KF (Eds), Dermatology in General Medicine. New York, McGraw-Hill, 1979, pp 1353-1363

21. Hollender MH, Abram HS: Dermatitis factitia South Med J 66:1279-1285, 1973

22. Lyell A: Dermatitis artefacta in relation to the syndrome of contrived disease. Clin Expt Dermatul 1:109-126, 1976

23. Spraker MK: Cutaneous artifactual disease: An ap- 
peal for help. Pediatric Clin North Am 30:659-668, 1983

24. Lyell A: Dermatitis artefacta and self-inflicted disease. Scot Med J 17:187-196, 1972

25. Ackerman AB, Mosher DT, Schwamm HA: Facticial Weber-Christian syndrome. JAMA 198:731-736, 1966

26. Gershwin ME, Gude JK, Petralli J: Factitious subcutaneous emphysema. Ann Intern Med 75:585-587, 1971

27. Dufton P, Griffiths A: Suction blisters mimicking pemphigoid-An unusual case of dermatitis artefacta. Clin Exp Dermatol 6:163-166, 1981

28. Agris J, Simmons CW: Factitious (self-inflicted) skin wounds. Plastic Reconstr Surg 62:686-692, 1978

29. Rees TD, Daniller A: Self-mutilation: Some problems in reconstruction. Plastic Reconstr Surg 43:300-303, 1969

30. Fabisch $W$ : What is dermatitis artefacta? Int J Dermatol 20:427-428, 1981

31. Shelley WB: Dermatitis artefacta induced in a patient by one of her multiple personalities. Br J Dermatol 105:587-589, 1981

32. Jones DPH: Dermatitis artefacta in mother and baby as child abuse. Br J Psychiatry 143:199-200, 1983

33. Stankler L: Factitious skin lesions in a mother and two sons. Br Med J 97:217-219, 1977

34. Halprin KM: The art of self-mutilation. III. Facticial dermatitis or dermatitis artefacta? JAMA 199:155, 1967

35. Novak M: Psychocutaneous medicine: Facticial dermatitis. Cutis 21:713-715, 1978

36. Obermayer ME: Psychocutaneous medicine. Springfield, IL, Charles C. Thomas, 1955, p 181

37. Seitz PFD: Psychocutaneous aspects of persistent pruritus and excessive excoriation. Arch Dermatol Syphilol 64:136-141, 1951

38. Fitzpatrick TB: Fundamentals of dermatologic diagnosis. In Fitzpatrick TB, Eisen AZ, Wolff K, Freedberg IM, Austen KF (eds), Dermatology in General Medicine, 2nd ed. New York, McGraw-Hill, 1979, p 32

39. Rajka $\mathrm{G}$ : Investigation of patients suffering from generalized pruritus, with special reference to systemic diseases. Acta Derm Venereol 49:190-194, 1966

40. Waisman M: Pickers, pluckers, and imposters, a panorama of cutaneous self-mutilation. Postgrad Med 38:620-630, 1965

41. Freunsgaard $K$, Nielsen $H$, Hjortshoj A: Controlled electroencephalographic investigations of patients with neurotic excoriations. Psychother Psychosom 34:273-281, 1980

42. Gupta MA, Gupta AK, Haberman HF: Neurotic excoriations: A review and some new perspectives. Compr Psychiatry 27:381-386, 1986

43. Levy DM: On the problem of movement restraint (tics, stereotyped movements, hyperactivity). Am J Orthopsychiatry 14:651-669, 1944

44. Musaph $\mathrm{H}$ : Psychodynamics in itching states. Int $\mathrm{J}$ Psychoanal 49:336-339, 1968

45. Van Dijk E, Van Voorst Vader PC: Dermatillomania. Dermatologica 158:65-71, 1979
46. Cormia FE: The role of psychosomatic factors in dermatoses. Conn Med J 14:1051-1061, 1950

47. Fisher BK: Neurotic excoriations. Can Med Assoc J 105:937-939, 1971

48. Levy SW: A psychosomatic approach to the management of recalcitrant dermatoses. Psychosomatics 4:334-337, 1963

49. Duke EE: Clinical experience with pimozide: Emphasis on its use in post-herpetic neuralgia. J Am Acad Dermatol 8:845-850, 1983

50. Krishnan KRR, Davidson JRT, Guajardo, C: Trichotillomania-A review. Compr Psychiatry 26:123-128, 1985

51. Mannino FV, Delgado RA: Trichotillomania in children: A review. Am J Psychiatry 126:505-511, 1969

52. Stewart WD, Danto JL, Maddin S: Dermatology, Diagnosis and Treatment of Cutaneous Disorders, 4th ed. St. Louis, Musby, 1978, pp 477-480

53. Domonkos AN, Arnold HL, Odom RB: Andrews' Diseases of the Skin, 7th ed. Philadelphia, Saunders, 1982, pp 56-74

54. Delgado PA, Mannino FV: Some observations on trichotillomania in children. J Am Acad Child Psychiatry 81:229-246, 1969

55. Taylor JG: A behavioral interpretation of obsessivecompulsive neurosis. Behav Res Ther 1:237-244, 1963

56. Bayer CA: Self-monitoring and mild aversion treatment of trichotillomania. J Behav Ther Exp Psychiatry 3:139-141, 1972

57. Horne DJ De L: Behaviour therapy for trichotillomania. Behav Res Ther 14:192-195, 1977

58. Ottens AJ: Multifaceted treatment of compulsive hair pulling. J Behav Ther Exp Psychiatry 12:77-80, 1981

59. Anthony $W$ : Brief intervention in a case of childhood trichotillomania by self-monitoring. J Behav Ther Exp Psychiatry 9:173-175, 1978

60. Rowen R: Hypnotic age regression in the treatment of a self-destructive habit: Trichotillomania. Am J Clin Hypnosis 23:195-197, 1981

61. McLaughlin J, Nay WR: Treatment of trichotillomania using positive coverants and response loss: $A$ case report. Behav Ther 6:87-91, 1975

62. Childers RT: Report of two cases of trichotillomania of longstanding duration and their response to chlorpromazine. J Clin Exp Psychopathol 19:141-144, 1958

63. Snyder S: Trichotillomania treated with amitriptyline. J Nerv Ment Dis 168:505-507, 1980

64. Krishnan KRR, Davidson JRT, Miller RD: MAO inhibitors in the treatment of trichotillomania associated with depression. J Clin Psychiatry 45:267-268, 1984

Direct reprint requests to:

M.A. Gupta, M.D.

Department of Psychiatry

University of Michigan Hospitals

Box 0704

1500 E. Medical Center Drive

Ann Arbor, MI 48109 